\title{
Association of Serum Uric Acid with Preeclampsia: A Case Control Study
}

\author{
Razia Sultana1, Selina Ahmed², Nasima Sultana ${ }^{3}$, S.M. Fazlul Karim4, Farhana Atia ${ }^{5}$
}

\begin{abstract}
Background: Preeclampsia (PE) is still one of the important causes of maternal and fetal mortality in Bangladesh. Many researches have been done to identify a unique screening test that would predict the risk of developing PE before the classic symptoms appear. One of the most accessible and easiest screening tests is serum uric acid measurement. Numerous studies have demonstrated a relation between elevated maternal serum uric acid levels and adverse maternal and fetal outcome. Among several pathophysiologic factors the most commonly accepted explanation for hyperuricemia in PE is increased reabsorption and decreased excretion of uric acid. Objective: The aim of the present study was to assess the association of serum uric acid with preeclampsia. Materials and method: A case control study was conducted in the department of Biochemistry, Dhaka Medical College, Dhaka from July 2010 to June 2011. A total number of 100 pregnant women in third trimester of pregnancy attending in Obstetrics and Gynaecology department of Dhaka Medical College Hospital were selected purposively as study subjects. Among them 50 pregnant women with preeclampsia were selected as cases and 50 normal healthy pregnant women as controls. Results: Most of the study subjects were within 21 - 30 years of age

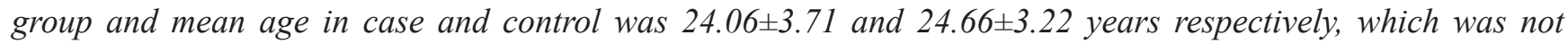
statistically different. Mean gestational age in case and control was $33.50 \pm 2.55$ weeks and $33.60 \pm 2.95$ weeks respectively, which was also not statistically different. Among the study subjects majority was primi in both groups (case 76\%, contol 58\%) showing no statistical significance. Majority of the subjects in both groups were irregular in their antenatal checkup (case 52\%, contol 40\%). Uric acid concentration was measured in all the study subjects. The mean serum uric acid concentration in cases and controls were $7.01 \pm 1.90 \mathrm{mg} / \mathrm{dl}$ and $4.55 \pm 1.63$ $\mathrm{mg} / \mathrm{dl}$ respectively. This difference was highly significant in statistical point of view. Conclusion: Hyperuricemia is associated with preeclampsia.
\end{abstract}

Keywords: Preeclampsia; uric acid.

Delta Med Col J.Jul 2013;1(2):46-50

1. Assistant Professor, Dept of Biochemistry, Delta Medical College, Dhaka, Bangladesh.

2. Professor and Head, Dept of Biochemistry, Popular Medical College, Dhaka, Bangladesh.

3. Professor and Head, Dept of Biochemistry, Dhaka Medical College, Dhaka, Bangladesh.

4. Professor and Head, Dept of Biochemistry, Delta Medical College, Dhaka, Bangladesh.

5. Medical Officer, Adhunik Sadar Hospital, Nilphamari, Bangladesh.

Correspondence: Dr. Razia Sultana. e-mail:lipiarf@yahoo.com

\section{Introduction}

Preeclampsia (PE) is still one of the important causes of maternal and fetal mortality. ${ }^{1}$ In Bangladesh, the incidence of $\mathrm{PE}$ is alarmingly high, about $16 \%$ of maternal deaths are associated with it. ${ }^{2} \mathrm{PE}$ is still regarded as a disease of theories and its etiology has remained poorly understood. However, endothelial dysfunction has been considered to play a central role in the pathophysiology of preeclampsia. ${ }^{3}$ Many researches have been done to identify a unique screening test that would predict the risk of developing $\mathrm{PE}$ before the classic symptoms appear. There is no screening test for PE to be reliable and economic. 
One of the most accessible and easiest screening tests is serum uric acid measurement. ${ }^{4}$ Several studies have demonstrated a correlation between elevated maternal serum uric acid levels and adverse maternal and fetal outcome. 5

Uric acid is a product of purine degradation catalyzed by the enzyme xanthine oxidase. Uric acid concentrations are influenced by several factors like high protein diet, alcohol consumption, increased cell turn over, enzyme defects in purine metabolism, altered kidney function, etc. In normal pregnant women serum uric acid concentration initially falls $25-35 \%$ due to elevation in renal clearance secondary to increased GFR or reduced proximal tubular reabsorption due to changes in its production rate. 6 Later in pregnancy the serum uric acid level increases possibly due to raised fetal production, decreased binding to albumin and a decline in uric acid clearance until towards the end of pregnancy when they approach non-pregnant value. 7 There are several potential origins for raised uric acid concentration in PE. It is usually secondary to altered renal function, increased tissue breakdown, increased oxidative stress and increased activity of xanthine oxidase. ${ }^{8}$ Uric acid is filtered, reabsorbed and secreted by the kidney. ${ }^{9}$ The most commonly accepted explanation for hyperuricemia in PE is increased reabsorption and decreased excretion of uric acid. 10

Uric acid has the ability to promote inflammation, oxidative stress and endothelial dysfunction which could promote hypertension, vascular disease and renal disease. An increased serum uric acid level indicates underlying oxidative stress. Increased oxidative stress and formation of Reactive Oxygen Species (ROS) have been proposed as another contributing source of hyperuricemia noted in PE apart from renal dysfunction. 10 Uric acid is a potent mediator of inflammation. Uric acid stimulates monocytes to produce pro-inflammatory cytokines IL-1 $\beta$, IL- 6 and TNF- $\alpha$. In preeclamptic women increased concentration of circulating TNF- $\alpha$ was positively correlated to circulating uric acid concentration. ${ }^{11}$ The analysis of a combination biochemical marker, particularly markers related to vascular dysfunction, such as increased uric acid concentration may enrich our ability to predict and prevent PE in near future. 12 Therefore, the present study was designed to assess the association of uric acid level in PE.

\section{Materials and method}

A case control study was conducted in the department of Biochemistry, Dhaka Medical College, Dhaka from July 2010 to June 2011. A total number of 100 pregnant women in third trimester of pregnancy attending in Obstetrics and Gynaecology department of Dhaka Medical College Hospital were selected purposively as study subjects. Among them 50 diagnosed cases of preeclampsia were selected as cases with age range of 18-35 years and 50 normal healthy age matched pregnant women as controls with range of 18-32 years. Pregnant women with pre-existing hypertension, diabetes mellitus and renal disease were excluded from the study by history, clinical examination and relevant laboratory investigations. After obtaining informed written consent from all the study subjects relevant data were documented in a predefined data sheet and maintaining all aseptic precaution blood samples were collected from all the study subjects for estimation of serum uric acid concentration. Serum uric acid level was estimated by colorimetric assay. Statistical analysis was performed by using computer based software, Statistical Package for Social Science (SPSS) for windows version 14. Mean values of different parameters were compared to see the differences between two groups by using Student's unpaired ' $\mathrm{t}$ ' test. Chi-square test was performed to find the statistical difference regarding gravida distribution between groups. For all statistical analysis, 'p' value $<0.05$ was considered as a lowest level of significance.

\section{Results}

Age distribution and comparison between groups are presented in Table I. Most of the subjects belonged to 21-30 years of age group (case $78 \%$, control $90 \%$ ). The mean \pm SD of age between case and control was $24.06 \pm 3.71$ years and $24.66 \pm 3.22$ years respectively. The difference was not statistically significant $(\mathrm{p}=0.39)$. 
Table I: Distribution and comparison of age in study subjects.

\begin{tabular}{lcccc}
\hline Age (years) & Case $(\mathbf{n}=\mathbf{5 0})$ & control $(\mathbf{n}=\mathbf{5 0})$ & t-value & p-value \\
\hline$\leq 20$ & $6(12 \%)$ & $3(6 \%)$ & & \\
$21-30$ & $39(78 \%)$ & $45(90 \%)$ & & \\
$31-40$ & $5(10 \%)$ & $2(4 \%)$ & & \\
Mean \pm SD & $24.06 \pm 3.71$ & $24.66 \pm 3.22$ & -0.86 & 0.39 \\
Range & $18-35$ & $18-32$ & & \\
\hline
\end{tabular}

Base line parameters in terms of gestational age, gravida and ante natal check up are shown in Table II, III and IV.

Mean \pm SD of gestational age in case and control was $33.50 \pm 2.55$ weeks and $33.60 \pm 2.95$ weeks respectively. On the other hand most of the subjects were primi both in case and control group. Both the parameters did not differ significantly $(p>0.05)$. Majority of the subjects in both groups had irregular antenatal check up.

Table II: Distribution and comparison of gestational age in study subjects

\begin{tabular}{lccc}
\hline $\begin{array}{l}\text { Study } \\
\text { subjects }\end{array}$ & $\begin{array}{c}\text { Gestational age (weeks) } \\
\text { Mean } \pm \text { SD }\end{array}$ & t-value & p-value \\
\hline Case $(\mathrm{n}=50)$ & $\begin{array}{c}33.50 \pm 2.55 \\
(29-38)\end{array}$ & & \\
& & -0.181 & 0.86 \\
Control $(\mathrm{n}=50)$ & $33.60 \pm 2.95$ & & \\
& $(30-38)$ & & \\
& &
\end{tabular}

Table III: Distribution and comparison of gravida in study subjects

\begin{tabular}{lcccc}
\hline \multirow{2}{*}{$\begin{array}{l}\text { Study } \\
\text { subjects }\end{array}$} & \multicolumn{2}{c}{ Gravida } & chi square & p-value \\
& Primi & Multi & value & \\
\hline Case $(\mathrm{n}=50)$ & $38(76 \%)$ & $12(24 \%)$ & & \\
Control $(\mathrm{n}=50)$ & $29(58 \%)$ & $21(42 \%)$ & & 0.06 \\
\hline
\end{tabular}

Table IV: Status of antenatal check up in study subjects

\begin{tabular}{lcc}
\hline Antenatal check up & Case $(\mathbf{n}=\mathbf{5 0})$ & Case $(\mathbf{n}=\mathbf{5 0})$ \\
\hline Regular & $2(4 \%)$ & $18(36 \%)$ \\
Irregular & $26(52 \%)$ & $20(40 \%)$ \\
None & $22(44 \%)$ & $12(24 \%)$ \\
\hline
\end{tabular}

Table $\mathrm{V}$ shows the comparison of serum uric acid concentration between cases and controls. Mean \pm SD serum uric acid level in cases and controls were $7.01 \pm 1.90 \mathrm{mg} / \mathrm{dl}$ and $4.55 \pm 1.63 \mathrm{mg} / \mathrm{dl}$ respectively. The level was significantly higher in cases than that of controls $(p=0.0001)$.

Table V: comparison of serum uric acid concentration between cases and controls

\begin{tabular}{lccc} 
Study subjects & $\begin{array}{c}\text { Serum uric acid }(\mathbf{m g} / \mathbf{d l}) \\
\text { Mean } \pm \text { SD }\end{array}$ & t-value & p-value \\
\hline Case $(\mathrm{n}=50)$ & $7.01 \pm 1.90$ & 6.97 & 0.0001 \\
Control $(\mathrm{n}=50)$ & $4.55 \pm 1.63$ & & \\
\end{tabular}

\section{Discussion}

The study was aimed to find the association between serum uric acid and preeclampsia. In the present study no statistically significant difference was observed between two groups regarding maternal age and gestational age.

The study reveals incidence of preeclampsia was high in primigravid. Similar conclusion was drawn by Odegard et al. ${ }^{13}$ where they showed nulliparity as a risk factor for preeclampsia.

Maximum number of cases and controls received irregular antenatal check up. The study reveals the frequency of regular antenatal check up is less in preeclamptic patients compared to normal pregnant women.

Hyperuricemia is a common finding in preeclamptic pregnancies evident from early pregnancy. Elevated serum uric acid concentrations were first noted in preeclamptic women in the late 1800 s. Since that time numerous reports have demonstrated a relationship between uric acid concentration and severity of the diseases. ${ }^{14}$ Severity of PE increases with increasing uric acid concentration. 6 Hyperuricemia is considered as a risk factor for hypertension, cardiovascular disease and renal disease, but the role of uric acid in the pathophysiology of PE is still not well understood. 
While this concept is largely unstudied, we expand upon ideas forwarded by Kang et al. 15 to share in the hypothesis that an elevated concentration of uric acid in preeclamptic women is not simply a marker of disease severity but rather contributes directly to the pathogenesis of disorder. In the present study, we have found that mean serum uric acid concentration were significantly higher in preeclamptic women than normal pregnant women. A good number of studies done previously had revealed similar findings.4,6,16 However, several other studies showed that serum uric acid is a poor predictor of PE.17-19 The development of methods to predict and prevent PE in early pregnancy is important for management of PE. Therefore, one of the most convenient screening tests for predicting $\mathrm{PE}$ is serum uric acid measurement.

Hyperuricemia is one of the most earliest and consistent observations in preeclamptic pregnancies. While elevated concentrations of circulating uric acid are not uniformly seen in every woman with PE, they do appear to identify a subset of preeclamptic women who are at greater risk for maternal and fetal mortalities. So, measurement of serum uric acid concentration seems to be useful test to predict maternal complications in the management of women with preeclampsia.

\section{References}

1. Sibai BM, Gordon T, Thom E. Risk factors for preeclampsia in healthy nulliparous women: a prospective multicenter study. The National Institute of Child Health and Human Development Network of Maternal - Fetal Medicine Units. Am J Obstet Gynecol. 1995;172: 642-48.

2. Rashid KM. Rahman M, Hyder S, editors. MCH and reproductive Health. Textbook of community Medicine and Public Health. 4th ed. Dhaka: RHM publishers; 2007.p. 155 .

3. Dekker GA, Sibai BM. Etiology and Pathogenesis of PE: Current concepts. AM J Obstet Gynecol. 1998;179(5):1359-75.

4. Aram SH, Khalilian A. The role of increased uric acid in predicting $\mathrm{PE}$ at the gestational age of $24-28$ weeks. Spring and Summer. 2007;1(1):65.
5. Lancet M, Fisher IL. The value of blood uric acid in toxemia of pregnancy. J Obstet Gynecol. 1956;63:116-19.

6. Brainbridge SA, Roberts JM. Uric acid as a pathogenic factor in preeclampsia. Placenta. 2008; 29:67-72.

7. Powers RW, Bodnar LM, Ness RB. Uric acid concentration in early pregnancy among preeclamptic women with gestational hyperuricemia at delivery. Am J Obstet Gynecol. 2006;194:160.

8. Johnson RJ, Kang DH, Feig D, Kivligh S, Kanellis J, Watanabe S, Tuttle KR, Rodriguez IB, Herrera AJ, Mazzali M. Is there a pathogenic role of uric acid in hypertension and cardiovascular and renal disease? Hypertension. 2003;41:1183-90.

9. Gallery ED, Hunyon SN, Gyory AZ. Plasma volume contraction: a significant factor in both pregnancy associated hypertension (preeclampsia) and chronic hypertension in pregnancy. Q J Med. 1979;48:593-602.

10. Many A, Hubel CA, Roberts JM. Hyperuricemia and xanthine oxidase in preeclampsia. Am J Obstet Gynecol. 1996;174:288-91.

11. Kannellis J, Watanabes S, Li JH, Kang DH, Li P, Nakagawa T, Wamsley A, Sheikh Hamad D, Lan HY, Feng L, Johnson RJ. Uric acid stimulates monocyte chemoattractant protein-1 production in vascular smooth muscle cells via mitogen activated protein kinase and cyclooxygenase - 2. Hypertension. $2003 ; 41: 1287-93$

12. Matsubara K, Matsubara Y, Masaharu ITO. The utility of vascular dysfunction studies in the prediction and prevention of preeclampsia: A historical review. Vascular disease prevention. 2009;6:163-69.

13. Odegard RA, Vatten LJ, Nilsen ST, Salvasen KA, Austgulen R. Risk factors and clinical manifestations of preeclampsia. Br J Obstet Gynecol. 2002;107:1410-16.

14. Voto LS, Illia R, Darbon- Grosso HA, Imaz FU, Margulies M. Uric acid levels: a useful index of the severity of preeclampsia and prenatal diagnosis. J Perinat Med. 1988;16(2):123-26. 
15. Kang DH, Finch J, Nakagawa T, Karumanchi SA, Kanellis J, Granger J, Johnson RJ. Uric acid, endothelial dysfunction and preeclampsia: searching for a pathogenic link. J Hypertens. 2004;22:229-35.

16. Kharb S. Uric acid and ascorbic acid levels in pregnancy with preeclampsia and diabetes. Webmed Central Biochemistry. 2010;1(10): WMC 00718.

17. Dekker GA, Sibai BM. Early prediction of preeclampsia. Am J Obstet Gynecol. 1998;165: 160-72.
18. Conde Agudelo A, lede R, Belizan J. Evaluation of methods used in the prediction of hypertensive disorders of pregnancy. Obstet Gynecol Surv. 1994;49:210-22.

19. William KP, Galerneau F. The role of serum uric acid as a prognostic indicator of the severity of maternal and fetal complications in hypertensive pregnancies. J Obstet Gynecol. 2002;24:628-32. 